Case report

\title{
6-year-old girl with anorectal malformation: what is more important - anatomy or function?
}

\author{
Dmitry A. Morozov ${ }^{1}$, Evgeniya S. Pimenova ${ }^{1,2}$, Darya S. Tarasova ${ }^{2}$, Darya D. Yakovenko ${ }^{1}$ \\ ${ }^{1}$ I.M. Sechenov First Moscow State Medical University, Moscow, Russia \\ ${ }^{2}$ G.N.Speransky City Children's Hospital №9, Moscow, Russia
}

Received 11 August 2017, Revised 30 October 2017, Accepted 12 November 2017

(C) 2017, Morozov D.A., Pimenova E.S., Tarasova D.S., Yakovenko D.D.

(C) 2017, Russian Open Medical Journal

Abstract: 6-year-old girl with first revealed anorectal malformation with perineal fistula was investigate. She did not have any complaints or history of constipation/soiling. Resting and squeeze anal pressure by anorectal manometry was normal. Recto-anal inhibitory reflex registered. There was no signs of dyssynergic defecation. The diameter of the colon by contrast enema was normal, megarectum did not detect, barium all came out after defecation. Muscles electro-identification confirmed external anal sphincter located posterior to the anus. After examination, council for Pediatric Surgery decided not to perform the surgery. Monitoring of the patient continued.

Keywords: non-operated anorectal malformation, physiology of defecation

Cite as Morozov D.A., Pimenova E.S., Tarasova D.S., Yakovenko D.D. 6-year-old girl with anorectal malformation: what is more important - anatomy or function? Russian Open Medical Journal 2018; 7: e0107.

Correspondence to Evgeniya S. Pimenova. Address: Department of Pediatric Surgery and Urology-Andrology, I.M. Sechenov First Moscow State Medical University, 8-2 Trubetskaya str., Moscow 119991, Russia. Phone: +7-985-265-33-02. E-mail: evgeniyapimenova@list.ru

\section{Introduction}

Anorectal malformations (ARM) are frequent congenital anomalies of anus, rectum and pelvic muscles with incidence ranging between 1 in 5000 births. Nowadays pediatric surgeons use Krickenbeck International classification of ARM based on a modification of fistula type and adding rare and regional variants $[1,2]$.

Perineal fistula is an anal malformation in which the anal opening is located anterior to the center of the sphincter. In females, the anal opening is located somewhere between the location of the normal sphincter and the female genitalia in the area known as the perineum or perineal body [3].

ARM in adults are rare. There are some case-reports about young persons with non-diagnostic ARM $[4,5]$ or long lasting stomas in patients [6]. It is very important that all of these patients had complaints - abdominal distension, constipation / fecal incontinence. We did not find any reports about non-operated ARM-patients with good functional property. Usually, children with ARM with perineal fistula had good development of pelvic floor muscles. However, functional fair and poor long-term results after anorectoplastic in low malformations are still high (10-53\% of cases). Typical problems are postoperative anal stenosis, constipation, secondary megacolon [7].

\section{Case Report}

We present the case-report of patient with non-operated ARM (perineal fistula) with good function of colon and pelvic floor muscles. A 6-year-old girl with ARM first revealed at the dispensary examination admitted to our hospital for investigation. Physical examination, anorectal manometry, barium enema and identification of the muscles by electric stimulator used. Examination conducted for the choice of surgical procedure.

The patient did not have a history of constipation or soiling, vulvitis. She presented without any complaints. The gluteal muscles had good development. The anus closed, located on the midline and anteriorly displaced next to vagina. Digital rectal examination detected that the «anus» had no stenosis.

Anorectal manometry showed normal resting and squeeze anal pressure. Normal recto-anal inhibitory reflex registered (basal anal pressure decreased more than $20 \%$ when rectal balloon inflated). There was no manometric signs of dyssynergic defecation - she generated a good pushing force (increase of intrarectal pressure) and simultaneously relaxed the distal pelvic muscles (decrease of anal pressure) (Figure 1).

Contrast enema demonstrated the normal diameter of the colon, large intestine had normal haustral pattern, barium all came out after defecation. There was no megarectum (Figure 2).

Muscles electroidentification detected that the external anal sphincter (EAS) located posterior to the anus/fistula (Figure 3).

The diagnosis - anorectal malformation with perineal fistula confirmed. After examination, we decided not to perform the surgical procedure and continue monitoring of the patient. She is monitored for eighteen months. Currently, she does not submit any complaints. The girl has defecation once a day without straining. There are no episodes of soiling. 
Identification of ARM with perineal fistula is an indication for surgical management [2]. This case demonstrate the good colonic function in child with congenital anatomical anorectal defect.

\section{Discussion}

How important is the anatomical structure of the muscles of the pelvic floor, rectum and anus to perform their function?

A. Pena, A. Bischoff (USA) with colleges have greatest experience of ARM treatment and officially declare: « ...through the years we found that what we observed as part of the sphincter mechanism in one patient was never the same as the one that we saw in another one...we are now certain to believe that we are dealing with a spectrum of anatomic variations...» [3]. Other authors posit that fecal continence depends on colonic transit time, rectal compliance, pelvic floor innervations, and interplay among the puborectalis muscle and anal sphincters. Loss of one or more of these functions can lead to fecal incontinence [8]. In our patient all of continence mechanisms are present and work, except external anal sphincter, and girl does not demonstrate fecal incontinence.

Known fact that internal anal sphincter (IAS) tonically contracted and relaxes as a consequence of reflex activity, predominantly during defecation. IAS relaxation occurs in response to rectal distension (the recto-anal inhibitory reflex). Relaxation allows the passage of distal rectal contents into the upper anal canal, enabling a conscious or subconscious perception of their physical nature [9]. IAS is very important in defecation and continence. The normal function and contribution of the EAS and IAS to anal continence can used to predict which muscles are abnormal in incontinent patients. IAS abnormality generally results in passive incontinence (i.e., the patient is unaware that leakage is about to occur) [10]. 30 years ago, researchers detected IAS, which surrounded the proximal part of the perineal fistulae in experiment [11]. There were normal manometric parameters of IAS in our girl. We assume that correct work of IAS in ARMpatients can provides normal defecation and fecal continence.

We agree with colleagues, who describe defecation as a difficult mechanism, which orchestrated by central, spinal, peripheral and enteric neural systems, acting on a morphologically intact gastrointestinal tract (including the final common path, the pelvic floor, and anal sphincters). Defecation is the act of voiding stool from the anus and it is influence by multiple factors, including colonic transit, stool volume and consistency, posture, age, gender, psychology and behavior, culture and lifestyle [12]. When the patient has a normal defecation, how important is the anatomical structure of his sphincters?

\section{Conclusion}

In our case, we decided not to use the surgery for patient with anatomical changes of anal sphincters with good colonic and pelvic floor function. Monitoring of the patient continued.

\section{Conflict of interest}

The authors declare that they have no conflict of interest.

\section{Ethical approval}

All procedures performed in studies involving human participants were in accordance with the ethical standards of the institutional research committee and with the 1964 Helsinki declaration and its later amendments or comparable ethical standards.

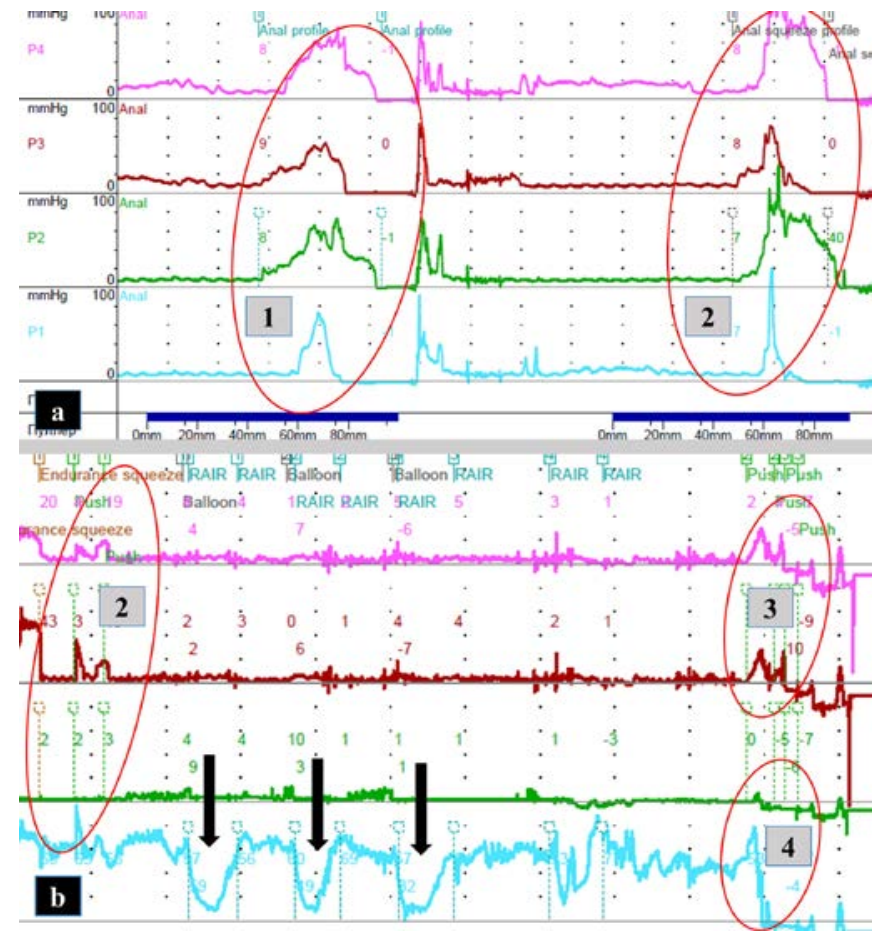

Figure 1. Anorectal manometry report: a - water-perfused manometry with four radial ports (pull-through technique); b -water-perfused manometry with balloon (stationary technique); 1 - anal profile (normal resting anal pressure - tonically contracted internal anal sphincter); 2 - squeeze anal profile (increase anal pressure by squeeze - contracted pelvic floor muscles); 3 - normal increase of intrarectal pressure during defecation; 4 - normal decrease of anal pressure during defecation. Black arrows - decrease of basal anal pressure when rectal balloon inflates (normal recto-anal inhibitory reflex).

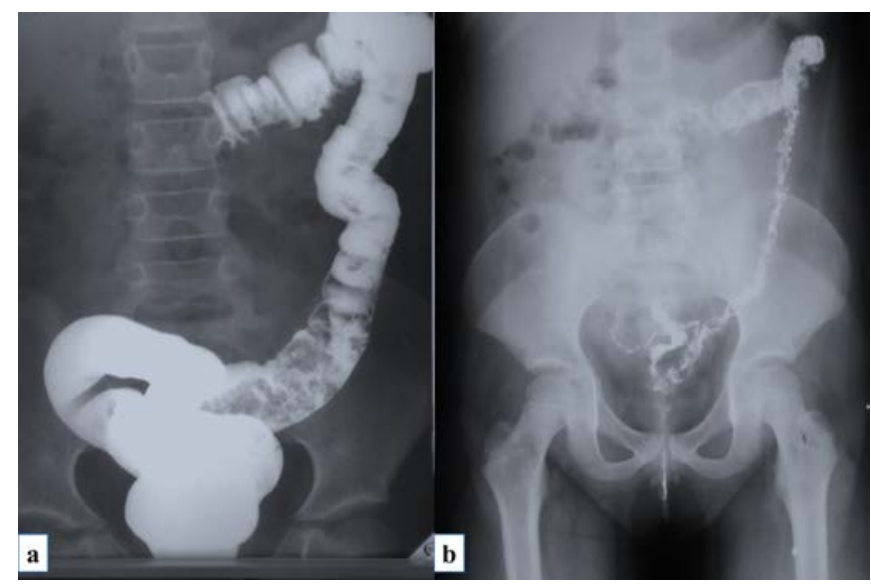

Figure 2. X- ray examination: a - contrast barium enema (front view); b post-evacuation radiograph (front view). 


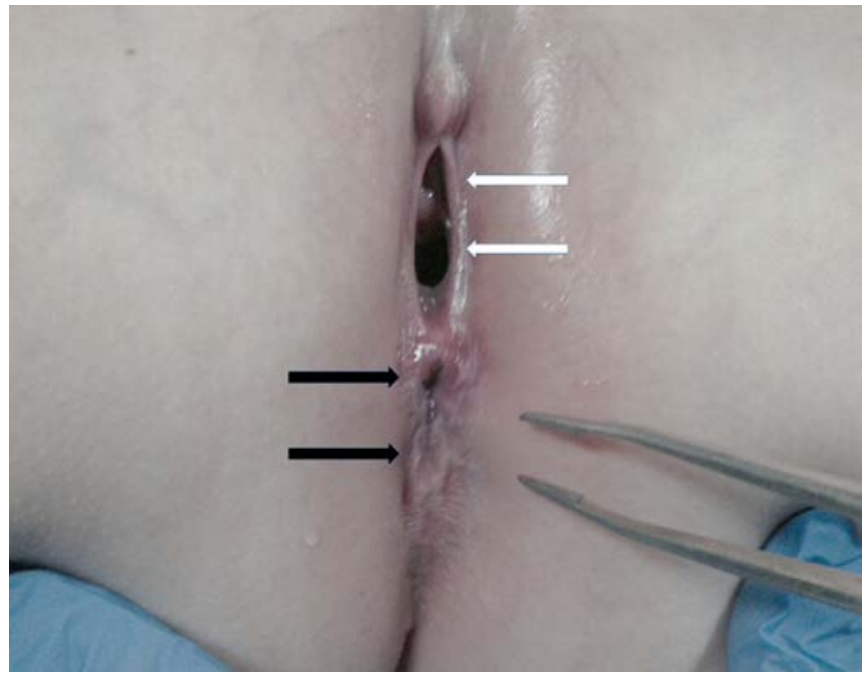

Figure 3. Local status of patient, identification of perineal muscles. Wight arrows - urethra and vagina. Upper black arrow - perineal fistula. Bottom black arrow - contracted dislocated EAS.

\section{References}

1. Holschneider A, Hutson J, Peña A, Beket E, Chatterjee S, Coran A, et al. Preliminary report on the International Conference for the Development of Standards for the Treatment of Anorectal Malformations. Journal of Pediatric Surgery 2005; 40 (10): 1521-1526. https://dx.doi.org/10.1016/j.jpedsurg.2005.08.002.

2. Averin VI, Ionov AL, Karavaeva SA, Komissarov IA, Kotin AN, Mokrushina OG, et al. Anorectal malformations in children (Federal Clinical Recommendations). Detskaya Khirurgiya 2015; 19(4): 29-35. Russian. https://elibrary.ru/item.asp?id=24003024.

3. Pena A, Bischoff A. Surgical treatment of colorectal problems in children. USA: Springer, 2015.

4. Miglani RK, Murthy D, Bhat RS, Ashok KK. Anorectal anomalies in adults-laparoscopic management and review of literature. Indian J Surg 2012; 74(4): 301-304. https://dx.doi.org/10.1007/s12262-0110394-3.

5. Chavan RN, Chikkala B, Das C, Biswas S, Sarkar DK, Pandey SK. Anorectal malformation: paediatric problem presenting in adult. Case Reports in Surgery 2015; 2015: 625474. https://dx.doi.org/10.1155/2015/625474.

6. Chakravartty S, Maity K, Ghosh D, Choudhury CR, Das S. Successful management in neglected cases of adult anorectal malformation. Singapore Med J 2009; 50(8): e280-e282. https://www.ncbi.nlm.nih.gov/pubmed/19710959.

7. Holschneider AM, Hutson JM. Anorectal malformations in children embryology, diagnosis, surgical treatment, follow-up. Berlin, Heidelberg: Springer, 2006.

8. Lentz GM, Krane M. 22. Anal incontinence. In: Lobo RA, Gershenson DM, Lentz GM, Valea FA. Comprehensive gynecology. Elsevier, 2017: 505-523.

9. Dickinson VA. Maintenance of anal continence: a review of pelvic floor physiology. Gut 1978; 19(12): 1163-1174. https://www.ncbi.nlm.nih.gov/pubmed/369960.

10. Halligan S. 20. Evaluation of the anal sphincter by anal EUS. In: Hawes RH, Fockens P, Varadarajulu Sh. Endosonography. Elsevier, 2015: 269281.

11. Lamprecht $\mathrm{W}$, Lierse $\mathrm{W}$. The internal sphincter in anorectal malformations: morphologic investigations in neonatal pigs. J Pediatr Surg 1987; 22: 11601168. https://www.ncbi.nlm.nih.gov/pubmed/3440904.
12. Palit S, Lunniss PJ, Scott SM. The physiology of human defecation. Dig Dis Sci 2012; 57: 1445-1464. https://dx.doi.org/10.1007/s10620-012 2071-1.

\section{Authors:}

Dmitry A. Morozov - MD, DSc, Professor, Head of the Department of Pediatric Surgery and Urology-Andrology, I.M. Sechenov First Moscow State Medical University, Moscow, Russia. http://orcid.org/0000-00021940-1395.

Evgeniya S. Pimenova - MD, PhD, Associate Professor, Department of Pediatric Surgery and Urology-Andrology, I.M. Sechenov First Moscow State Medical University, Moscow, Russia; Pediatric Surgeon, G.N. Speransky City Children's Hospital №9, Moscow, Russia. http://orcid.org/0000-0001-7206-5987.

Darya S. Tarasova - MD, Pediatric Surgeon, G.N. Speransky City Children's Hospital №9, Moscow, Russia. http://orcid.org/0000-0003-2387-8740.

Darya D. Yakovenko - Student, Pediatric Faculty, I.M. Sechenov First Moscow State Medical University, Moscow, Russia. http://orcid.org/00000001-9342-2517. 